\title{
Association of Death Anxiety with Spiritual Well-Being and Religious Coping in Older Adults During the COVID-19 Pandemic
}

\author{
Mohammad Rababa ${ }^{1}$ D Audai A. Hayajneh ${ }^{1} \cdot$ Wegdan Bani-Iss $^{2}$
}

Accepted: 29 October 2020 / Published online: 7 December 2020

(c) Springer Science+Business Media, LLC, part of Springer Nature 2020

\begin{abstract}
This descriptive study aimed to examine the association of death anxiety with religious coping and spiritual well-being among 248 community-dwelling older adults during the COVID-19 pandemic. The brief Arab religious coping scale, the Arabic version of the spiritual well-being Scale, and the Arabic Scale of death anxiety were used to measure religious coping, spiritual well-being, and death anxiety, respectively. The majority of the participating older adults were found to have low levels of religious coping and spiritual well-being and high levels of death anxiety. Further, in comparison to male older adults, female older adults were found to have higher levels of religious coping and lower levels of death anxiety. Moreover, in comparison to widowed older adults, married older adults were found to have higher levels of death anxiety. After controlling for sociodemographic characteristics, religious coping, and spiritual well-being were found to be significant predictors of death anxiety in older adults.
\end{abstract}

Keywords Death anxiety · Spiritual well-being · Religious coping · COVID-19 . Older adults

\section{Introduction}

On March 11, 2020, the World Health Organization (WHO) announced the coronavirus disease (COVID-19) a global pandemic, which was subsequently confirmed by a United States (US) National Emergency declaration on March 13, 2020 (Armitage

Mohammad Rababa

mjrababa@just.edu.jo

1 Department of Adult Health Nursing, Faculty of Nursing, Jordan University of Science and Technology, Irbid, P.O. Box 3030, 22110, Jordan

2 Department of Nursing, College of Health Sciences, Research Institute for Medical and Health Sciences/Health Promotion Research Group, University of Sharjah, P.O. Box 27272, Sharjah, United Arab Emirates 
and Nellums 2020). By May 22, 2020, over 5.11 million people worldwide had been infected with COVID-19, with more than 333,000 deaths (D'Adamo et al. 2020). Further, COVID-19 has caused dramatic collapses in healthcare systems around the world, leading to significant losses of health and life, particularly for older adults who require intensive care (D'Adamo et al. 2020). The initial reports from Wuhan revealed that more than half of all COVID-19 confirmed cases were among older adults, who have higher morbidity and mortality rates than other age groups ( $\mathrm{Li}$ et al. 2020). Medical reports from Italy and the US, which are both suffering from a high burden of COVID-19 cases, have also revealed that high case-fatality rates of COVID-19 are significantly associated with advanced age, with most death cases occurring among people aged 60 years and over (Onder, Rezza and Brusaferro 2020). Many research studies and reports have confirmed that older adults are the most vulnerable age group to COVID-19 (Onder et al. 2020; Covid and Team 2020), and that COVID-19 significantly impacts all aspects of older adults' quality of life (Hall Laddu Phillips Lavie and Arena 2020). One of these impacted aspects is older adults' mental health, including anxiety (Kim and Kim 2019). Death anxiety means persistent, abnormal, and panic fear of dying (Bala and Maheshwari 2019).

Although it is natural for older adults to experience death anxiety (DA), the COVID-19 pandemic has exacerbated feelings of death anxiety in older adults, leading to catastrophic consequences on older adults' body functions in general and their immunity in particular (Chatard Renoux Monéger Jaafari and Selimbegovic 2020). Such consequences can lead to dramatic increases in morbidity and mortality rates among older adults (Chatard et al. 2020).

Death anxiety has been associated with adverse health consequences, including the decrease in physical functions, psychological stress, impaired ego integrity, weakening of religious beliefs, life dissatisfaction, and poor resilience (Semenova and Stadtlander 2016). Further, Death anxiety is associated with the exposure to life-threatening events (Hoelterhoff and Chung 2013). For example, ElizarrarásRivas et al. (2010) found that people who witnessed their family members or relatives being diagnosed with H1N1 influenza and suffering from its symptoms experienced high levels of death anxiety, and Safren et al. (2003) reported similar findings among HIV-positive older adults. However, while many studies have explored death anxiety in older adults as a result of life-threatening infectious diseases such as the H1N1 influenza and HIV (Hoelterhoff and Chung 2013; Safren Gershuny and Hendriksen 2003; Elizarrarás-Rivas et al. 2010), the current study is the first to explore death anxiety experienced by older adults during the COVID-19 pandemic. Further, the association of death anxiety with certain sociodemographic characteristics, religious coping, and spiritual well-being among older adults during the COVID-19 pandemic has never been examined. Moreover, the related studies in the literature were not conducted on older adults exclusively and have reported limited and conflicting findings on the influence of sociodemographic variables such as gender and marital status on religiosity, spirituality, and death anxiety among older adults (Bassett and Bussard 2018; Henrie and Patrick 2014).

It is imperative to investigate religious coping and spiritual well-being and how they relate to death anxiety among older adults during the COVID-19 pandemic. With social distancing being one of the effective ways of limiting the 
spread of COVID-19, religious practices in Mosques and Churches were suspended (Eisazadeh Aliakbari Dehkordi and Aghajanbigloo 2020). Consequently, the religious coping and spiritual well-being of older adults have been dramatically and negatively impacted, and it is expected that their levels of death anxiety have increased (Eisazadeh et al. 2020). A better understanding of the interaction between religious coping, spiritual well-being, and death anxiety would help researchers in the field of nursing understand how the religious coping and spiritual well-being of older adults could be enhanced under such exceptional circumstances in order to decrease older adults' death anxiety and its associated COVID-19 related morbidity and mortality (Lu et al. 2020). Further, crosscultural research studies on death anxiety among older adults in the Middle East are limited.

Religious coping behaviors, such as praying, are usually carried out for managing distressing and stressful situations (Jong 2020). Many research studies have confirmed the effectiveness of such religious coping behaviors in helping people manage their feelings of distress and anxiety, as they allow people to cope with guilt, submit totally to God's will, view affliction in a positive light, and control their fear (Chatard et al. 2020; Rosmarin and Leidl 2020; Vishkin and Tamir 2020). Religious coping has been found to be a buffer against death anxiety and may work as a mechanism that interrupts the cycle of the negative consequences of death anxiety. Religious coping enhances optimism and hope, which in turn inhibit death anxiety (Vishkin and Tamir 2020).

It is essential to consider the spiritual well-being of older adults during a stressful and life-threatening situation such as the COVID-19 pandemic. The meaning of spirituality varies and is not limited to religious practices (MacLeod Wilson Crandall and Austin 2019). Spirituality is defined as the "dynamic and intrinsic aspect of humanity through which persons seek meaning and purpose as well as relationships to self, family, others, and community" (MacLeod et al. 2019, p. 4). "Spirituality" exists inside both religious and secular people and promotes a positive sense of inner peace and healing (Rosmarin and Leidl 2020). Spiritual well-being, the perfect development of spiritual abilities, is crucial for the optimal management of death anxiety. Even in adverse circumstances, improved spirituality can reduce fear of death, allow people to overcome hardships, and improve people's satisfaction with their life (Vasigh arjomanand Borjiet 2018).

Although studies in the literature have reported multiple findings, death anxiety in older adults is generally associated with their sociodemographic characteristics (e.g., gender and marital status), spirituality, and religiosity. However, studies conducted in Muslim countries have not targeted older adults specifically. Therefore, due to the minimal evidence and contradictory findings of recent studies on death anxiety in the literature, this study aimed to examine the association of death anxiety with religious coping and spiritual well-being among older adults during the COVID-19 pandemic. As a secondary purpose, we are interested in examining the differences in the study's main variables based on older adults' sociodemographic characteristics such as gender and marital status. 


\section{Methods}

\section{Study Type and Settings}

This was a descriptive study.

\section{Sample Size and Sampling}

Two hundred and forty-eight community-dwelling older adults aged between 60 to 75 years were included in the study. This age category was selected in order to rule out any potential confounding effects of cognitive impairment or memory loss (McParland Kelly and Innes 2017). The sample size was determined based on a-priori $\mathrm{G}^{*}$ power analysis using GPower 3.1 software for the independent sample $t$-test (Faul Erdfelder Lang and Buchner, 2007). Given a significance level of $\alpha=0.05$, an estimated effect size of 0.5 (Cohen 2013), and a statistical power level of 0.95 , the minimum required sample size was 236 . An additional 12 older adults were recruited to control for any potential dropouts.

\section{Ethical Consideration}

The researchers obtained ethical approval (IRB \# 399-2020) from the Institutional Review Board (IRB) of Jordan University of Science and Technology. Following the IRB approval and before the initiation of any study procedures, written informed consent was obtained from the participants. Throughout the data collection process, the participants were ensured that their participation was voluntary, and that they could withdraw from the study at any time without consequences or penalties. The participants' personal information was kept anonymous and was not disclosed to anyone, and the collected data were kept private and confidential.

\section{Measures}

\section{Death Anxiety}

Death anxiety was measured using the Arabic Scale of Death Anxiety (ASDA), which was validated in a research study conducted in three Arab countries (AbdelKhalek Lester Maltby and Tomás-Sábado 2009). The ASDA includes 20 statements answered on a 5-point intensity scale (ranging from $1=$ "No" to $5=$ "Very much"). The total possible score of the ASDA ranges from 20 to 100, with higher scores indicating greater death anxiety levels. In the original study, the ASDA had very satisfactory Cronbach's alpha reliability scores ranging from 0.88 to 0.93, and good internal consistency scores ranging from 0.74 to 0.90 . Compared to Templer's DAS, the ASDA had high convergent validity scores which ranged 
from 0.60 to 0.74 (Abdel-Khalek et al. 2009). In the current study, the internal consistency reliability of the ASDA was satisfactory (Cronbach's alpha $=0.78$ ).

\section{Spiritual Well-Being}

Spiritual well-being was measured using the Arabic version (Musa and Pevalin 2012) of the Spiritual Well-Being Scale (SWBS; Ellison 1983). The SWBS consists of 20 items answered on a six-point scale ranging from ' $1=$ strongly disagree' to ' $6=$ strongly agree'. The total possible score of the SWBS was calculated by adding together the possible responses of all of the items after reverse coding the negative items (e.g. "I do not enjoy much about life"). The total possible score ranges from 20 to 120 , with higher scores indicating greater levels of spiritual well-being. The face and construct validity of the original SWBS were established in the original study (Ellison 1983), and the validity of the Arabic version of the SWBS was demonstrated among a sample of Arab older adults (Musa and Pevalin 2012). The Cronbach's alpha reliability of the Arabic version of the SWBS was 0.87 in the study of Musa and Pevalin (2012). Also, in the current study, the internal consistency reliability of the SWBS was excellent (Cronbach's alpha=0.87).

\section{Religious Coping}

Religious coping was measured using the brief Arab religious coping scale (BARCS; Amer Hovey Fox and Rezcallah 2008). The BARCS consists of 15 items answered on a four-point scale ranging from ' $0=$ not used at all/does not apply' to ' $3=$ used always'. The total score of the BARCS was calculated by adding together the possible responses of all of the items. The total possible score ranges from 0 to 75 , with higher scores indicating greater levels of religious coping. The BARCS has demonstrated strong face validity and satisfactory construct validity (Amer et al. 2008). The Cronbach's alpha for the BARCS in the original study was 0.94 (Amer et al. 2008). The Cronbach's alpha reliability of the BARCS in the current study was 0.85 .

\section{Demographic Characteristics}

The participating older adults' demographic data, such as age (continuous variable), gender (female/male), marital status (married/widowed), employment (yes/no), education (finished high-school/below high-school/Bachelor's degree or higher), employment (yes/no), and number of people living in the same household (continuous variable), were collected by asking the participants to fill out the demographic questionnaire.

\section{Data Collection}

Following the IRB approval, the researcher sent a message to all nursing students through the university email portal system, encouraging them to invite their parents or grandparents who met the eligibility criteria to participate in the study. 
This message also contained brief information about the study purpose and procedures and the participants' rights and responsibilities. Further, the message contained a request for students whose parents or grandparents agreed to participate in the study to reply with their phone numbers and convenient dates/times to schedule a phone interview with the research assistant. Due to the lockdown in Jordan, all study data were collected over the phone and directly documented on the designated spaces on each participant's questionnaire. The average time of each phone call was $15 \mathrm{~min}$.

\section{Statistical Analysis}

The Statistical Package for the Social Sciences (SPSS version 25.0 (Armonk, NY: IBM Corp) was used for all statistical analyses. Descriptive statistics were used to describe the older adults' demographic characteristics and levels of religious coping, spiritual well-being, and death anxiety. Independent two-sample t-tests were used to examine the differences in the main variables according to the participants' gender (female vs. male) and marital status (married vs. widowed). T-test analysis was not conducted for education, employment, or religion due to the small sample sizes in the comparison groups. Hierarchical regression was used to examine the association between death anxiety and levels of religious coping and spiritual well-being after controlling for gender and marital status. The Pearson correlation indicated that there was no association between age and death anxiety; therefore, age was not included in the regression model. As indicated by the results of the t-test (Table 2), only the significant independent variables gender and marital status were entered into the model.

\section{Results}

\section{The Participants' Demographic Characteristics and the Mean Scores of the Study Variables}

At the beginning of the study, 258 older adults were recruited. Ten participants were excluded due to unfinished questionnaires, resulting in a total of 248 participants and a response rate of $90.9 \%$. The ages of the participants ranged from 60 to 68 years $(M=93.95, \mathrm{SD}=2.9)$. The number of people living in the same household with the participants ranged from 1 to 5 people $(M=1.6, \mathrm{SD}=0.6)$. Of the 248 participants, 105 (42.3\%) were female, $142(57.3 \%)$ were married, 228 had not completed high school, 97.9\% were retired, and 95.9\% were Muslim. The findings showed that most of the participants had below-average levels of religious coping $(M=36.15, \mathrm{SD}=6.8)$ and spiritual well-being $(M=52.01$, $\mathrm{SD}=17.5)$ and high levels of death anxiety $((M=68.76, \mathrm{SD}=19.2)$. The descriptive statistics of the participants are outlined in Table 1. 
Table 1 Descriptive statistics of the participants' demographics, ASDA, BARCS, SWBS scores $(n=248)$

\begin{tabular}{|c|c|c|}
\hline \multirow[t]{2}{*}{ Characteristics } & \multicolumn{2}{|c|}{ Participants } \\
\hline & $N$ & $\%$ \\
\hline \multicolumn{3}{|l|}{ Gender } \\
\hline Female & 105 & 42.3 \\
\hline Male & 143 & 57.7 \\
\hline \multicolumn{3}{|l|}{ Marital status } \\
\hline Widowed & 106 & 42.7 \\
\hline Married & 142 & 57.3 \\
\hline \multicolumn{3}{|l|}{ Education } \\
\hline Completed high school & 11 & 4.5 \\
\hline Below high school & 228 & 91.9 \\
\hline Bachelor's degree and higher & 9 & 3.6 \\
\hline \multicolumn{3}{|l|}{ Employment } \\
\hline No & 243 & 97.9 \\
\hline Yes & 5 & 2.1 \\
\hline \multicolumn{3}{|l|}{ Religion } \\
\hline Islam & 238 & 95.9 \\
\hline \multirow[t]{2}{*}{ Christianity } & 10 & 4.1 \\
\hline & Mean & $\mathrm{SD}$ \\
\hline Age & 63.95 & 2.9 \\
\hline Number of people living in the same household & 6.3 & 2.5 \\
\hline Total ASDA scores & 68.76 & 19.2 \\
\hline Total BARC scores & 36.15 & 6.8 \\
\hline Total SWBS scores & 52.01 & 17.5 \\
\hline
\end{tabular}

ASDA Arabic scale of death anxiety, BARC Brief arab religious coping scale, SWBS Spiritual well-being scale $S D$ Standard deviation

Table 2 Group differences based on demographic data $(N=248)$

\begin{tabular}{|c|c|c|c|c|c|c|c|c|c|}
\hline \multirow[t]{2}{*}{ Nurse groups } & \multicolumn{3}{|c|}{ Spiritual well-being } & \multicolumn{3}{|c|}{ Religious coping } & \multicolumn{3}{|c|}{ Death anxiety } \\
\hline & Mean & $\mathrm{SD}$ & $t$ & Mean & SD & $t$ & Mean & SD & $t$ \\
\hline \multicolumn{10}{|l|}{ Gender } \\
\hline Female & 50.40 & 19.9 & 1.25 & 36.99 & 7.8 & $3.72 * *$ & 58.80 & 16.6 & $-7.26^{* *}$ \\
\hline Male & 53.20 & 15.3 & & 33.80 & 5.7 & & 76.07 & 19.8 & \\
\hline \multicolumn{10}{|l|}{ Marital status } \\
\hline Widowed & 51.97 & 17.6 & 0.04 & 35.1 & 6.8 & 0.12 & 71.11 & 18.9 & $2.12 *$ \\
\hline Married & 52.07 & 17.3 & & 35.2 & 6.9 & & 65.60 & 21.8 & \\
\hline
\end{tabular}

SD Standard deviation

*Significant difference at $p \leq 0.05 ; * *$ Significant difference at $p \leq 0.001$ 


\section{Differences Between the Study Groups}

As shown in Table 2, the independent two-sample t-test analysis revealed significant gender-based differences in the participants' levels of religious coping and death anxiety: $\left(t_{246}=3.72, p<0.001\right)$ and $\left(t_{245}=-7.26, p<0.001\right)$, respectively. In comparison to male older adults, female older adults reported higher levels of religious coping and lower levels of death anxiety. Further, the independent two-sample t-test analysis revealed a significant difference between the death anxiety levels of married older adults and those of widowed older adults $\left(t_{246}=2.12, p=0.035\right)$. Based on the analysis, married older adults had higher levels of death anxiety.

\section{Predictors of Death Anxiety in Older Adults}

Hierarchical multiple regression was used to assess whether religious coping and spiritual well-being are predictors of death anxiety in older adults after controlling for gender and marital status. The participants' demographics, including gender and marital status, were entered into Model 1, and religious coping and spiritual wellbeing levels were entered into Model 2. The relative contributions of religious coping and spiritual well-being as predictors of older adults' death anxiety are summarized in Table 3. As shown in Table 3, after controlling for gender and marital status in step 2, the religious coping and spiritual well-being levels of the participants accounted for $2.3 \%$ of the variance in death anxiety. Overall demographics, religious coping, and spiritual well-being predicted $22.5 \%$ of the variance in the participants' death anxiety.

\section{Discussion}

The current study is the first study conducted in the Middle East to examine older adults' death anxiety and its associated factors during the COVID-19 pandemic. This study found older adults' levels of religious coping, spiritual well-being, and

Table 3 Hierarchical regression analysis with the death anxiety Scores $(N=248)$

\begin{tabular}{|c|c|c|c|c|c|}
\hline Step and predictor variable & $R^{2}$ & $\Delta R^{2}$ & $\beta$ & $t$ & $p$ \\
\hline Step 1 & .202 & .202 & & & \\
\hline Marital status & & & -6.640 & -2.828 & .005 \\
\hline Gender & & & 17.695 & 7.231 & $<.001$ \\
\hline Step 2 & .225 & .023 & & & \\
\hline Marital status & & & -6.521 & -2.806 & .005 \\
\hline Gender & & & 16.695 & 6.981 & $<.001$ \\
\hline Spiritual well-being & & & -.140 & -1.986 & .048 \\
\hline Religious coping & & & -.434 & -2.365 & .019 \\
\hline$F_{(4,243)}=17.67, p<.001$ & & & & & \\
\hline
\end{tabular}


death anxiety to vary significantly based on the selected sociodemographic characteristics. Further, the results indicated significant associations between death anxiety and certain sociodemographic characteristics, religious coping levels, and spiritual well-being levels in older adults.

Consistent with previous studies conducted on similar population groups during other pandemic conditions, such as HIV/AIDS and the H1N1 influenza (Hoelterhoff and Chung 2013; Safren et al. 2003; Elizarrarás-Rivas et al. 2010), older adults in the current study had high levels of death anxiety. Several explanations may be suggested for these high levels of death anxiety. Due to the rapid progress and high case-fatality of COVID-19, billions of older adults over the world, especially those with chronic illnesses, have been experiencing fear of death (Le Couteur, Anderson and Newman 2020). From the beginning of the pandemic and up until now, older adults have had the highest fatality rate (Le Couteur Anderson and Newman 2020). However, the older adults' mean ASDA score (68.76 out of 100) in the current study was higher than that of previous studies which applied the same scale on other populations of Muslim older adults (Dadfar Lesterand Bahrami 2016). In comparison to many other countries around the world, Jordan has a low COVID-19 mortality rate; however, the dramatically increasing COVID-19 mortality rates recorded in neighboring countries like Saudi Arabia may have contributed to the high levels of death anxiety reported in the current study (Alahdal Basingab and Alotaibi 2020).

Most older adults in this study reported low levels of religious coping, which is in agreement with the findings of a previous study conducted among Muslim older adults (Henrie and Patrick 2014). However, due to the lockdown applied in Jordan during the COVID-19 pandemic and due to people therefore being unable to attend religious services, the older adults in this study had even lower religious coping levels than documented in previous studies (Eisazadeh et al. 2020). This finding supports the findings of a previous study, which reported a negative association between the religious coping of older adults and their religious service attendance (Bassett and Bussard 2018; Byrne and Morgan 2020). According to Islamic tradition, it is acceptable for Muslims to practice religious rituals, such as prayer, at home; however, attending congregational prayers at the mosque has been suggested by many studies as being a form of group coping therapy (Bolghan-Abadi Ghofrani and Abde-Khodaei 2014; Iqbal Zaman Karandikar Hendrickse and Bowley 2016; Padela Killawi Heisler Demonnerand Fetters 2011). Some studies have also suggested that in stressful events such as the death of a loved one, older adults experience religious doubt, which negatively impacts their religious coping (Henrie and Patrick 2014).

The older adults in this study reported low levels of spiritual well-being, which is consistent with previous studies which have investigated the association between spirituality and death anxiety (MacLeod et al. 2019; Solaimanizadeh Mohammadinia and Solaimanizadeh 2019). A recent study by Solaimanizadeh et al. (2019) found an adverse relationship between spirituality and death anxiety among older adults. Therefore, due to their high levels of COVID-19-related death anxiety, it was expected that our study participants would have low levels of spiritual wellbeing. Also, the participants' low levels of spiritual well-being may be explained by the low levels of life satisfaction and disturbed sense of the meaning and purpose of 
life experienced by people during the COVID-19 pandemic, as reported by many studies (Zhang Wang Rauch and Wei 2020a, b).

Previous studies which have examined gender-based differences in death anxiety under non-pandemic conditions have shown women to experience higher levels of death anxiety than men (Azaiza Ron Shoham and Gigini 2010; MacLeod Crandall Wilson and Austin 2016). These studies relied on the emotional expressiveness hypothesis to explain their findings, stating that females are more aware of their feelings and more willing to acknowledge their fears explicitly than are males (Azaiza et al. 2010). In contradiction to these findings but consistent with the findings of a recent study by Dadfar Abdel-Khalek Lester and Atef Vahid (2017), the current study found male older adults to have higher levels of death anxiety than female older adults. This finding may be explained by the high COVID-19 morbidity and mortality rates among male older adults. According to recent epidemiology reports, the prevalence of COVID-19 infection is higher among males, especially those aged over 60 years (Edler et al. 2020; Shim Tariq Choi Lee and Chowell 2020). The crude case-fatality rate of COVID-19 increases with age, with male older adults being more likely to die from the disease than female older adults (Zhang Yu Tong Liu and Tang 2020a, b).

In the current study, female older adults had higher levels of religious coping than male older adults. This finding is consistent with previous studies, in which female seniors reported higher levels of religiousness than did male seniors (Garg Chauhan and Sabreen 2018; Handal and Lace 2017; Henrie and Patrick 2014). This finding is also consistent with terror management theory (TMT), which states that being male is positively associated with religious doubt and negatively associated with religiousness (Henrie and Patrick 2014). In the current study, this finding may be attributed to men being prevented from attending congregational prayers at the mosque due to the lockdown.

As with regards to the mean SWBQ score, female older adults, in comparison to male older adults, were found to have higher levels of spiritual well-being. This finding is consistent with the findings of previous studies (Alorani and Alradaydeh 2018; Martins Dias Domingues and Caldeira 2020; Musa Pevalin and Shahin 2016). For example, Martins et al. (2020) found that gender plays a significant impact on the spiritual well-being of cancer patients undergoing chemotherapy. These findings may be attributed to gender-based differences in life experiences, coping strategies, and social roles (Hammermeister Flint Alayli Ridnour and Peterson 2005).

In the current study, widowed older adults had significantly higher death anxiety levels than married older adults. This supports the finding of Khawar Aslam and Aamir (2013), which indicated that married older adults tend to often worry about dying and leaving their loved partner behind with no one to care for them. Meanwhile, widowed older adults have been reported to be less concerned about their own death (Waskowic and Chartier 2003). According to Momtaz Haron Ibrahim and Hamid (2015), widowed participants agreed that they had come to terms with their own death, and that they would be ready to die with the time came. 


\section{Predictors of Death Anxiety}

In the current study and in line with previous studies, comorbid burden, spiritual well-being, and religious coping were significantly associated with death anxiety after controlling for gender and marital status. Solaimanizadeh et al. (2019) found a significant negative association between spiritual well-being and death anxiety. In comparison to people with low levels of spiritual well-being, people with high levels of spiritual well-being have been found to be more capable of controlling their feelings of pervasive anxiety associated with both the real and anticipated death of themselves or their loved ones (MacLeod et al. 2019). In other words, the higher the level of spiritual well-being that older adults have, the lower their level of death anxiety. When older adults are spiritually well, they experience positive feelings about their current stressful situation and a strong inner healing force (Soleimani Sharif Yaghoobzadeh Yeoh and Panarello 2018). According to Bakan Arliand Y1ldı (2019), religious coping was found to be among the most important predictors of death anxiety in older adults. Holding strong religious views have been negatively associated with experiencing death anxiety (Bassett and Bussard 2018). Religious coping can therefore help protect individuals from death anxiety, which is consistent with terror management theory (TMT) (Vail et al. 2010). TMT hypothesizes that the leading role of religion is to help individuals relieve the anticipated anxiety associated with mortality salience, which refers to people's awareness of their inevitable mortality (Martins et al. 2020).

Further research which targets other population groups, such as college students and health professionals, is recommended. Also, further research is recommended in order to develop interventions which target death anxiety, impaired spirituality, and maladaptive religious coping strategies among older adults during the COVID-19 pandemic. Ongoing spiritual skills training for healthcare providers is essential in situations such as the COVID-19 pandemic, as it will allow healthcare providers to relieve the death anxiety and associated psychological distress experienced by older adults and their families. Therefore, spiritual skills need to be acknowledged as a core clinical competency for nurses and incorporated in nursing curricula. Further, it is highly recommended that chaplains and imams provide in-hospital religious services for older adults diagnosed with COVID-19. Finally, mosques and churches are encouraged to maintain their contact with believers during the COVID-19 pandemic using advanced technologies and the public media.

\section{Limitation}

This study used a convenience sampling technique, which may limit the external validity and therefore threaten the generalizability of the results. Further, instances of miscommunication may have occurred during the process of collecting data over the phone and then using the data to fill in the participants' questionnaires. 


\section{Conclusion}

The current study confirmed the significant association of death anxiety with spiritual well-being and religious coping in older adults during the COVID-19 pandemic. Therefore, there is an urgent need for future studies which assess and evaluate older adults' spiritual and religious needs and which implement intervention programs, in Jordan and in other countries, to target older adults' death anxiety during the COVID-19 pandemic.

Funding Funding was provided by Jordan University of Science and Technology (Grant No. 20200449).

\section{References}

Abdel-Khalek, A. M., Lester, D., Maltby, J., \& Tomás-Sábado, J. (2009). The Arabic scale of death anxiety: some results from east and west. OMEGA-Journal of Death and Dying, 59(1), 39-50.

Alahdal, H., Basingab, F., \& Alotaibi, R. (2020). An analytical study on the awareness, attitude and practice during the COVID-19 pandemic in Riyadh Saudi Arabia. Journal of Infection and Public Health. https://doi.org/10.1016/j.jiph.2020.06.015

Alorani, O. I., \& Alradaydeh, M. T. F. (2018). Spiritual well-being, perceived social support, and life satisfaction among university students. International Journal of Adolescence and Youth, 23(3), 291-298.

Amer, M. M., Hovey, J. D., Fox, C. M., \& Rezcallah, A. (2008). Initial development of the brief Arab religious coping scale (BARCS). Journal of Muslim Mental Health, 3(1), 69-88.

Armitage, R., \& Nellums, L. B. (2020). COVID-19 and the consequences of isolating the elderly. The Lancet Public Health, 5(5), 256.

Azaiza, F., Ron, P., Shoham, M., \& Gigini, I. (2010). Death and dying anxiety among elderly Arab Muslims in Israel. Death Studies, 34(4), 351-364.

Bakan, A. B., Arli, S. K., \& Yıldız, M. (2019). Relationship between religious orientation and death anxiety in elderly individuals. Journal of Religion and Health, 58(6), 2241-2250.

Bala, R., \& Maheshwari, S. K. (2019). Death anxiety and death depression among elderly. International Journal of Psychiatric Nursing, 5(1), 55-59.

Bassett, J. F., \& Bussard, M. L. (2018). Examining the complex relation among religion, morality, and death anxiety: Religion can be a source of comfort and concern regarding fears of death. OMEGA-Journal of Death and Dying. https://doi.org/10.1177/0030222818819343.

Bolghan-Abadi, M., Ghofrani, F., \& Abde-Khodaei, M. S. (2014). Study of the spiritual intelligence role in predicting university students' quality of life. Journal of Religion and Health, 53(1), 79-85.

Byrne, C. M., \& Morgan, D. D. (2020). Patterns of religiosity, death anxiety, and hope in a population of community-dwelling palliative care patients in new Zealand-what gives hope if religion can't? American Journal of Hospice and Palliative Medicine ${ }^{\circledR}, 37(5), 377-384$.

Chatard, A., Renoux, M., Monéger, J., \& Selimbegovic, L. (2020). Physical warmth attenuates ethnocentric bias under mortality salience: An embodied terror management perspective. https://doi. org/10.31234/osf.io/x6m8u.

Cohen, J. (2013). Statistical power analysis for the behavioral sciences. Cambridge: Academic press.

Covid, C. D. C., \& Team, R. (2020). Severe outcomes among patients with coronavirus disease 2019 (COVID-19)-United States, February 12-March 16, 2020. MMWR Morbidity and Mortality Weekly Report, 69(12), 343-346.

D'Adamo, H., Yoshikawa, T., \& Ouslander, J. G. (2020). Coronavirus disease 2019 in geriatrics and long-term care: The ABCDs of COVID-19. Journal of the American Geriatrics Society, 68(5), 912-917. 
Dadfar, M., Abdel-Khalek, A. M., Lester, D., \& Atef Vahid, M. K. (2017). The psychometric parameters of the Farsi form of the Arabic Scale of Death Anxiety. The Scientific World Journal. https ://doi.org/10.1155/2017/7468217

Dadfar, M., Lester, D., \& Bahrami, F. (2016). Death anxiety, reliability, validity, and factorial structure of the Farsi form of the Arabic scale of death anxiety in Iranian old-aged persons. Journal of Aging Research, 2016, 2906857. https://doi.org/10.1155/2016/2906857

Edler, C., Schröder, A. S., Aepfelbacher, M., Fitzek, A., Heinemann, A., Heinrich, F., \& Püschel, K. (2020). Dying with SARS-CoV-2 infection-an autopsy study of the first consecutive 80 cases in Hamburg, Germany. International Journal of Legal Medicine, 134, 1275-1284.

Eisazadeh, F., Aliakbari Dehkordi, M., \& Aghajanbigloo, S. (2020). Psychological consequences of patients with coronavirus (COVID-19): A Qualitative study. Biquarterly Iranian Journal of Health Psychology, 2(2), 9-20.

Elizarrarás-Rivas, J., Vargas-Mendoza, J. E., Mayoral-García, M., Matadamas-Zarate, C., ElizarrarásCruz, A., Taylor, M., \& Agho, K. (2010). Psychological response of family members of patients hospitalised for influenza A/H1N1 in Oaxaca. Mexico. BMC Psychiatry, 10(1), 104. https://doi. org/10.1186/1471-244X-10-104

Ellison, C. W. (1983). Spiritual well-being: Conceptualization and measurement. Journal of Psychology \& Theology, 11, 330-340.

Faul, F., Erdfelder, E., Lang, A. G., \& Buchner, A. (2007). G* Power 3: A flexible statistical power analysis program for the social, behavioral, and biomedical sciences. Behavior Research Methods, 39(2), 175-191.

Garg, R., Chauhan, V., \& Sabreen, B. (2018). Coping styles and life satisfaction in palliative care. Indian Journal of Palliative Care, 24(4), 491-495.

Handal, P. J., \& Lace, J. W. (2017). Differential effects of family structure on religion and spirituality of emerging adult males and females. Journal of Religion and Health, 56(4), 1361-1370.

Hall, G., Laddu, D. R., Phillips, S. A., Lavie, C. J., \& Arena, R. (2020). A tale of two pandemics: How will COVID-19 and global trends in physical inactivity and sedentary behavior affect one another? Progress in Cardiovascular Diseases. https://doi.org/10.1016/j.pcad.2020.04.005

Hammermeister, J., Flint, M., El-Alayli, A., Ridnour, H., \& Peterson, M. (2005). Gender differences in spiritual well-being: Are females more spiritually-well than males? American Journal of Health Studies, 20(1/2), 80-84.

Henrie, J., \& Patrick, J. H. (2014). Religiousness, religious doubt, and death anxiety. The International Journal of Aging and Human Development, 78(3), 203-227.

Hoelterhoff, M., \& Chung, M. C. (2013). Death anxiety and well-being; coping with life-threatening events. Traumatology, 19(4), 280-291.

Iqbal, F., Zaman, S., Karandikar, S., Hendrickse, C., \& Bowley, D. M. (2016). Engaging with faith councils to develop stoma-specific fatawās: a novel approach to the healthcare needs of muslim colorectal patients. Journal of Religion and Health, 55(3), 803-811.

Jong, J. (2020). Death anxiety and religious belief: A critical review. In C. Routledge \& K. Vail III (Eds.), The science of religion, spirituality, and existentialism (pp. 21-35). Amsterdam, NL: Elsevier.

Khawar, M., Aslam, N., \& Aamir, S. (2013). Perceived social support and death anxiety among patients with chronic diseases. Pakistan Journal of Medical Research, 52(3), 75-79.

Kim, Y., \& Kim, M. (2019). Factors influencing death anxiety in community-dwelling elderly: Based on the ecology theory. The Korean Journal of Hospice and Palliative Care, 22(1), 30-38.

Le Couteur, D. G., Anderson, R. M., \& Newman, A. B. (2020). COVID-19 through the lens of gerontology. The Journals of Gerontology. Series A, Biological Sciences and Medical Sciences, 75(9), e119-e120. https://doi.org/10.1093/gerona/glaa077.

Li, Q., Guan, X., Wu, P., Wang, X., Zhou, L., Tong, Y., \& Xing, X. (2020). Early transmission dynamics in Wuhan, China, of novel coronavirus-infected pneumonia. New England Journal of Medicine, 382(13), 1199-1207.

Lu, H., Nie, P., \& Qian, L. (2020). Do quarantine experiences and attitudes towards COVID-19 affect the distribution of mental health in China? A quantile regression analysis. Applied Research in Quality of Life. https://doi.org/10.1007/s11482-020-09851-0.

MacLeod, R., Crandall, J., Wilson, D., \& Austin, P. (2016). Death anxiety among New Zealanders: The predictive role of gender and marital status. Mental Health, Religion \& Culture, 19(4), 339-349.

MacLeod, R., Wilson, D. M., Crandall, J., \& Austin, P. (2019). Death anxiety among new Zealanders: The predictive roles of religion, spirituality, and family connection. OMEGA-Journal of Death and Dying, 80(1), 3-19. 
Martins, H., Dias Domingues, T., \& Caldeira, S. (2020). Spiritual well-being in cancer patients undergoing chemotherapy in an outpatient setting: A cross-sectional study. Journal of Holistic Nursing, $38(1), 68-77$.

McParland, P., Kelly, F., \& Innes, A. (2017). Dichotomising dementia: Is there another way? Sociology of Health \& Illness, 39(2), 258-269.

Momtaz, Y. A., Haron, S. A., Ibrahim, R., \& Hamid, T. A. (2015). Spousal death anxiety in old age: Gender perspective. OMEGA-Journal of Death and Dying, 72(1), 69-80.

Musa, A. S., \& Pevalin, D. J. (2012). An Arabic version of the spiritual well-being scale. International Journal for the Psychology of Religion, 22(2), 119-134.

Musa, A. S., Pevalin, D. J., \& Shahin, F. I. (2016). Impact of spiritual well-being, spiritual perspective, and religiosity on the self-rated health of Jordanian Arab Christians. Journal of Transcultural Nursing, 27(6), 550-557.

Onder, G., Rezza, G., \& Brusaferro, S. (2020). Case-fatality rate and characteristics of patients dying in relation to COVID-19 in Italy. JAMA, 323(18), 1775-1776.

Padela, A. I., Killawi, A., Heisler, M., Demonner, S., \& Fetters, M. D. (2011). The role of imams in American Muslim health: Perspectives of Muslim community leaders in Southeast Michigan. Journal of Religion and Health, 50(2), 359-373.

Rosmarin, D. H., \& Leidl, B. (2020). Spirituality, religion, and anxiety disorders. In D. H. Rosmarin \& H. G. Koenig (Eds.), Handbook of spirituality, religion, and mental health (pp. 41-60). Academic Press (Elsevier).

Safren, S. A., Gershuny, B. S., \& Hendriksen, E. (2003). Symptoms of posttraumatic stress and death anxiety in persons with HIV and medication adherence difficulties. AIDS Patient Care and STDs, 17(12), 657-664.

Shim, E., Tariq, A., Choi, W., Lee, Y., \& Chowell, G. (2020). Transmission potential and severity of COVID-19 in South Korea. International Journal of Infectious Diseases, 93, 339-344.

Solaimanizadeh, F., Mohammadinia, N., \& Solaimanizadeh, L. (2019). The relationship between spiritual health and religious coping with death anxiety in the elderly. Journal of Religion and Health, 59, $1925-1932$.

Soleimani, M. A., Sharif, S. P., Yaghoobzadeh, A., Yeoh, K. K., \& Panarello, B. (2018). Exploring the relationship between spiritual well-being and death anxiety in survivors of acute myocardial infarction: moderating role of sex, marital status and social support. Journal of Religion and Health, $57(2), 683-703$.

Semenova, V., \& Stadtlander, L. (2016). Death anxiety, depression, and coping in family caregivers. Journal of Social, Behavioral, and Health Sciences, 10(1), 34-48.

Vail, K. E., Rothschild, Z. K., Weise, D. R., Solomon, S., Pyszczynski, T., \& Greenberg, J. (2010). A terror management analysis of the psychological functions of religion. Personality and Social Psychology Review, 14(1), 84-94.

Vasigh, A., Tarjoman, A., \& Borji, M. (2018). The effect of spiritual-religious interventions on patients' pain status: Systematic review. Anaesthesia, Pain \& Intensive Care, 22(4), 499-505.

Vishkin, A., \& Tamir, M. (2020). Fear not: Religion and emotion regulation in coping with existential concerns. In K. E. Vail III \& C. Routledge (Eds.), The science of religion, spirituality, and existentialism (pp. 325-338). Oxford, UK: Elsevier.

Waskowic, T. D., \& Chartier, B. M. (2003). Attachment and the experience of grief following the loss of a spouse. OMEGA-Journal of Death and Dying, 47(1), 77-91.

Zhang, J., Yu, M., Tong, S., Liu, L. Y., \& Tang, L. V. (2020). Predictive factors for disease progression in hospitalized patients with coronavirus disease 2019 in Wuhan China. Journal of Clinical Virology. https://doi.org/10.1016/j.jcv.2020.104392

Zhang, S. X., Wang, Y., Rauch, A., \& Wei, F. (2020). Unprecedented disruption of lives and work: Health, distress and life satisfaction of working adults in China one month into the COVID-19 outbreak. Psychiatry Research. https://doi.org/10.1016/j.psychres.2020.112958

Publisher's Note Springer Nature remains neutral with regard to jurisdictional claims in published maps and institutional affiliations. 